\title{
Guideline adherence for the treatment of advanced schistosomiasis japonica in Hubei, China
}

\author{
Fangying Zhong $\cdot$ Chenxi Liu $\cdot$ Xinping Zhang
}

Received: 27 August 2014 / Accepted: 23 September 2014 / Published online: 2 October 2014

(C) The Author(s) 2014. This article is published with open access at Springerlink.com

\begin{abstract}
This study compared physicians' practices on three treatment procedures and hospitalization days with guideline recommendations to assess guideline adherence in the treatment of advanced schistosomiasis japonica. Descriptive statistics were used to estimate patients' characteristics and rate of guideline adherence. And chi-square tests were used to assess influences of severity of the disease on guideline adherence. The study found no one $(0 / 173)$ adhered to adequate diagnosis, treatment regimens, and discharge criteria of guidelines completely. And $2.23 \%$ of patients in group 1 and $4.23 \%$ in group 2 were totally conforming to adequate diagnosis. $91.91 \%$ of patients were conforming to adequate treatment regimens among which group 1 and group 2 were 90.32 and $92.25 \%$, respectively. And one $(2.23 \%)$ patient in group 1 and zero ( $0 \%$ ) in group 2 were conforming to discharge criteria of guidelines, and most of the patients left hospital without symptom checks (151/173), liver function and biochemical tests (169/173), and complication checks (91/173). Among 173 inpatients, rate of adequate hospitalization days was $36.42 \%(63 / 173)$. And chi-square test suggested no significant difference $(P>0.05)$ on guideline adherence in two groups, which implied both of critical and general patients' treatments should be stressed to comply with guidelines. There existed a large gap between guidelines and practices of the treatment of advanced schistosomiasis japonica.
\end{abstract}

Keywords Guideline adherence · Physicians' compliance . Advanced schistosomiasis japonica

F. Zhong $\cdot$ C. Liu $\cdot$ X. Zhang $(\bowtie)$

School of Medicine and Health Management, Tongji Medical

College, HuaZhong University of Science and Technology, No. 13

Hangkong Road, Wuhan, Hubei, China

e-mail: xpzhang602@163.com

\section{Introduction}

Clinical practice guidelines have proliferated in recent decades as an attempt to improve the effectiveness and efficiency of health care (McCormack and Loewen 2007). Emphasis on the development and implementation of guidelines has been fueled by research documenting high rates of inappropriate care and wide variations in clinical practice for common health care conditions (McGlynn et al. 2003; Bampton et al. 2007). Adherence to clinical practice guidelines is advocated as a method to decrease utilization of ineffective therapies and increase adoption of evidence-based practices, ultimately resulting in improved patient outcomes and more costeffective care. Belief in the ability of guidelines to improve quality of care has led to a rapid proliferation in the number of guidelines available for a wide variety of clinical conditions (Larson 2003; Walter et al. 2009; Moonen and Cohe 2011). Although the primary goal of clinical practice guidelines is to improve quality, few of researches have actually examined the impact of adherence to guideline recommendations on clinical diagnosis, treatment regimens, and discharge criteria (Fritz et al. 2007).

Schistosomiasis affects about 74 countries and regions containing 200 million people worldwide, and more than 650 million people live in endemic areas. Several million people all over the world suffer from severe morbidity as a consequence of schistosomiasis. Its infections impose a great burden on poor populations in the developing world (WHO 2006). China is an endemic area of schistosoma japonica and one of the four countries most seriously harmed by schistosomiasis in the globe (Ren 2009; Zhu et al. 2010). Much billion Yuan was expended to control the disease, with the majority of costs related to prevention as well as prescription medication. Like other common conditions, inappropriate variations in care and unacceptably high use of ineffective therapies might lead to serious organic injury or complication such as upper 
gastrointestinal bleeding (UGB) (Chen 2002). All of the above calls for increased adherence to clinical practice guidelines of schistosomiasis.

Although all patients with schistosomiasis seek care and receive therapy in the local lazaret or the designated hospital and they are managed in local Center for Disease Control and Prevention (CDC), there still exists incorrect and unreliable diagnosis, etc. (Feng et al. 2011). Because of serious consequence of schistosomiasis, many clinical practice guidelines have been developed to direct primary care providers towards more evidence-based management (Lugtenberg 2011). Guidelines provide a series of active criteria for clinical diagnosis and treatment regimens so that passive treatment could be minimized (Hope et al. 2008). Therefore, adherence to guidelines by clinicians managing patients with schistosomiasis has been of great concern.

The principle of diagnosis and treatment guideline is accordant with most patients, so guideline adherence should be promoted (Shao 2012; Fenwick et al. 2009). However, study exploring the adherence to guideline recommendations of schistosomiasis is lacking. Most researches have examined the impact of adherence on costs and process-related variables (Cretin et al. 2007). The study took clinical diagnosis, treatment regimens, and discharge criteria into consideration and analyzed the targets in relation to guideline adherence. And our study, by presetting a research hypothesis, devoted that there was approving guideline adherence in the treatment of patients with advanced schistosomiasis. The main purpose of this study was to examine adherence to the guideline recommendations for the practice provided by physicians to patients with advanced schistosomiasis and finally to promote rational and adequate schistosomiasis care.

\section{Methods}

The criteria for evaluating guideline adherence

Guidelines for the study reference are the Ministry of Health of the People's Republic of China (Diagnostic Criteria for Schistosomiasis) and Disease Prevention and Control Department of the Ministry of Health of the People's Republic of China (Schistosomiasis Control Manual (the third edition)). On the basis of the guidelines above, a criteria was formulated for the adherence study as shown in Table 1 (Schwentner et al. 2013). The criteria contained guideline recommendations of three treatment procedures, which were diagnosis, treatment regimens, and discharge check, respectively. According to the criteria, we did a comparative analysis with the actual treatment for patients with advanced schistosomiasis japonica.
Study population

A retrospective study of patients with advanced schistosomiasis japonica was conducted from July 2013 to February 2014. Patients with advanced schistosomiasis at two Chinese representative hospitals including Gong'an Schistosomiasis Special Hospital and Shishou Third People's Hospital were included in the study and eligible if they (1) were not seriously ill or without any other disorder; (2) do not have serious schistosomiasis complications and organic diseases, hepatitis, or any other liver dysfunction; (3) were over 4 years of age (WHO 2006); (4) were without history of adverse drug reactions; and (5) have complete medical records.

\section{Data collection}

One hundred seventy-three patients' general characteristics, which contained sex, age, state of health, job, and history of disease, were recorded at admission from January 2010 to November 2013. We would assess the guideline adherence in the treatment for patients with advanced schistosomiasis japonica. So, the related diagnosis, treatment regimens, and discharge check of these patients were collected by rule and line.

Because the severity of disease was one of the most important factors which influenced the practices of physicians' diagnosis and treatment behavior (Chen 2007; Ma and Zhong 2004), the study divided the 173 patients into two groups. Group 1 comprises 31 critical patients, and group 2 comprises 142 general patients according to severity of advanced schistosomiasis japonica.

\section{Statistical analysis}

Descriptive statistics were used to estimate patients' characteristics in the study population and to compare the two groups according to their characteristics concordance status. To further elucidate the impact of guideline adherence, we calculated the rate of adequate diagnosis, treatment regimens, and discharge check, respectively, and the total rate of all the three procedures conforming to guideline recommendations as seen in the following formulas. Then, for the above three procedures, chi-square tests were used to assess differences between the two groups, when appropriate. All tests were bilateral, and a $P$ value of $<0.05$ was considered statistically significant. Statistical analyses were performed using Statistical Package for the Social Sciences (SPSS) 13.0. Finally, through comparative analysis, guideline adherence would be stated clearly. Rate of adequate $A *=$ Total number of adequate $A * /$ Total number of $A \times 100 \%(* A$ represented diagnosis, treatment regimens, and discharge check, respectively.) Total rate $=$ Total number of all the three procedures conforming to guidelines/Total number in the study $\times 100 \%$ 
Table 1 The criteria for evaluating guideline adherence based on Diagnostic Criteria for Schistosomiasis and Schistosomiasis Control Manual (the third edition)

\begin{tabular}{|c|c|c|}
\hline & Conforming to guideline & Nonconforming to guideline \\
\hline \multicolumn{3}{|l|}{ Diagnosis } \\
\hline History of infected water contact & $\begin{array}{l}\text { Duration of contact with infected water or prior } \\
\text { schistosomiasis treatment }\end{array}$ & $\begin{array}{l}\text { Neither duration of contact with infected water } \\
\text { nor prior schistosomiasis treatment }\end{array}$ \\
\hline Clinical manifestations & Portal hypertension, dwarf or colonic granuloma & $\begin{array}{l}\text { Without portal hypertension, dwarf and } \\
\text { colonic granuloma }\end{array}$ \\
\hline Etiological examination & Find worm eggs or miracidium & Never find worm eggs or miracidium \\
\hline Immunologic test & $\begin{array}{l}\text { Patients without history of schistosomiasis treatment } \\
\text { or with more than } 2 \text { years of treatment: IHA } \geq 1: 10 \text {, } \\
\text { one or more of ELISA, DIGFA, and DDIA were } \\
\text { positive }\end{array}$ & $\begin{array}{l}\text { Patients without history of schistosomiasis treatment } \\
\text { or with more than } 2 \text { years of treatment: IHA }<1: 10, \\
\text { all of ELISA, DIGFA, and DDIA were negative }\end{array}$ \\
\hline \multicolumn{3}{|l|}{ Treatment regimens } \\
\hline No praziquantel therapy & Taking & Non-taking \\
\hline Liver-protecting therapy & Taking hepatinica & Not taking hepatinica \\
\hline Symptomatic therapy & Done & Not done \\
\hline \multicolumn{3}{|l|}{ Discharge criteria, hospitalization days } \\
\hline Patient's state on discharge & Vital signs turning normal & Vital signs not turning normal \\
\hline Symptom check & No fever, no abdominal pain, etc. & Fever, abdominal pain, etc. \\
\hline Liver function and biochemical test & Turning normal & Not turning normal \\
\hline Complications & No severe complications & Severe complications \\
\hline Hospitalization days & $10 \sim 15$ days & $<10$ or $>15$ days \\
\hline
\end{tabular}

\section{Results}

\section{General characteristics}

A total of 173 patients with advanced schistosomiasis japonica were studied, 106 of whom were males. Thirty-one patients were included in group 1, and the others were in group 2 (Table 2). There was no statistical significance in terms of sex, age, state of health, job, and history of disease of the patients between group 1 and group 2. Thus, all of the above analysis demonstrated that there was good comparability in the two groups.

\section{Overall guideline adherence}

The study found that only one $(2.23 \%)$ patient in group 1 was totally in accordance with adequate diagnosis or discharge criteria. And 28 (90.32\%) patients' treatment regimens were adequate in the group. Besides, there were $6(4.23 \%)$, $131(92.25 \%)$, and $0(0 \%)$ patients, respectively, that conform to adequate diagnosis, treatment regimens, and discharge criteria. What is more, no one $(0 / 173)$ was conforming to adequate diagnosis, treatment regimens, and discharge criteria according to guidelines at the same time (Table 3).

\section{Adherence of diagnosis}

Table 4 showed the distribution of four diagnosis practices according to guidelines in the two groups. The rate of adequate recommendation to check history of infected water contact was the highest, which of two groups were 96.77 and $95.77 \%$, separately. Physicians' compliance with

Table 2 The characteristics of the study groups based on 31 critical patients and 142 general patients with advanced schistosomiasis japonica included in the study

\begin{tabular}{|c|c|c|c|c|c|}
\hline & & Group 1 & Group 2 & $\chi^{2}$ & $P$ value \\
\hline \multirow[t]{2}{*}{ Sex } & Male & 15 & 91 & \multirow[t]{2}{*}{2.642} & \multirow[t]{2}{*}{$0.104 P$} \\
\hline & Female & 16 & 51 & & \\
\hline \multirow[t]{3}{*}{ Age } & $40 \leq$ & 0 & 13 & \multirow[t]{3}{*}{5.388} & \multirow[t]{3}{*}{$0.068 P$} \\
\hline & $40-60$ & 12 & 69 & & \\
\hline & $\geq 60$ & 19 & 60 & & \\
\hline \multirow[t]{3}{*}{ State of health } & Good & 2 & 9 & \multirow[t]{3}{*}{0.089} & \multirow[t]{3}{*}{$0.956 P$} \\
\hline & General & 24 & 113 & & \\
\hline & Poor & 5 & 20 & & \\
\hline \multirow[t]{2}{*}{ Job } & Farmer & 30 & 140 & \multirow[t]{2}{*}{0.428} & \multirow[t]{2}{*}{$0.681 F$} \\
\hline & Else & 1 & 2 & & \\
\hline \multirow[t]{2}{*}{ History of disease } & No & 0 & 15 & \multirow[t]{2}{*}{3.586} & \multirow[t]{2}{*}{$0.058 P$} \\
\hline & Yes & 31 & 127 & & \\
\hline
\end{tabular}

$F$ Fisher's exact test, $P$ Pearson's chi-square test 
Table 3 The rate of adequate procedure according to guidelines

\begin{tabular}{llllll}
\hline Adequate procedure & Group 1 & Rate $^{\mathrm{a}}(\%)$ & Group 2 & Rate (\%) & Total rate (\%) \\
\hline Diagnosis & 1 & 2.23 & 6 & 4.23 & $0(0 / 173)$ \\
Treatment regimens & 28 & 90.32 & 131 & 92.25 & 0 \\
Discharge criteria & 1 & 2.23 & 0 & 0 \\
\hline
\end{tabular}

${ }^{\mathrm{a}}$ Rate represents the rate of adequate procedure

diagnosis recommendations for clinical manifestation check and etiological examination was on the low side. As for immunologic test, the study found the rate is $70.97 \%$ in group 1 and $65.49 \%$ in group 2 . Finally, the chi-square test suggested there was no significant difference $(P>0.05)$ on guideline adherence of the four diagnoses in the two groups.

\section{Adherence of treatment regimens}

Through statistics, there was a high rate of adequate treatment regimens. In group 1, $100 \%$ treatment regimens of liverprotecting therapy and no praziquantel therapy were conforming to guidelines, and $28(90.32 \%)$ regimens of symptomatic therapy complied with the guidelines. As for group 2, the rate of three treatment regimens in accordance with guidelines was $99.30,100$, and $92.96 \%$, respectively. Besides, the chi-square test showed there was no significant difference $(P=0.614)$ on symptomatic therapy in the two groups (Table 5).

Adherence of discharge criteria and hospitalization days

Table 6 showed the compliance with guidelines to check patient's state on discharge was good, as the rate was 96.77 and $97.89 \%$ in the two groups. In contrast, the rate of adequate symptom check and liver function and biochemical test was low. Discharge checks of $13(41.94 \%)$ patients in group 1 and 69 (48.59\%) in group 2 were conforming to guidelines to check complications. Besides, the chi-square test showed there was no significant difference $(P>0.05)$ on guideline adherence of the four discharge checks in the two groups.
Among the 173 inpatients, the rate of adequate hospitalization days was $36.42 \%(63 / 173)$. The other inpatients received the hospitalization care more than 15 days or less than 10 days. The rate of group 1 and group 2 was $29.03 \%(9 / 31)$ and $38.03 \%(54 / 142)$ separately, and there was no significant difference $(0.346)$ between the two through chi-square test.

\section{Discussion}

Guideline recommendations may be based on either scientific evidence or the expertise of the guideline developers via a consensus decision-making process (Marciano et al. 2014). In order to cure patients with advanced schistosomiasis japonica better, authorized guidelines should be adhered by physicians to standardize treatment procedures. The primary objective of this study was to assess concordance based on the guideline recommendations for the practice provided by physicians to patients with advanced schistosomiasis.

The study found that no one $(0 / 173)$ adhered to adequate diagnosis, treatment regimens, and discharge criteria according to guidelines at the same time. And only $2.23 \%$ patients in group 1 and $4.23 \%$ ones in group 2 were totally conforming to adequate diagnosis. However, the above nonstandard behaviors of diagnosis practice would be reasons for misdiagnosis (Chen 2007). Previous researches had found that misdiagnosis could and did occur and was reasonably common with error rates ranging from $1.4 \%$ to a high $20-40 \%$ misdiagnosis rate, and surveys of patients also indicated the chance of experiencing a misdiagnosis to range from 8 to $40 \%$ (Right Diagnosis 2014; Reed and May 2011). Besides, a high
Table 4 Guideline adherence of diagnosis recommendations

\begin{tabular}{llllllll}
\hline & & Group 1 & Rate (\%) & Group 2 & Rate (\%) & $\chi^{2}$ & $P$ value \\
\hline History of infected water contact & Yes & 30 & 96.77 & 136 & 95.77 & 0.065 & 0.798 \\
& No & 1 & & 6 & & & \\
Clinical manifestations & Yes & 6 & 19.35 & 28 & 19.72 & 0.002 & 0.963 \\
& No & 25 & & 114 & & & \\
Etiological examination & Yes & 11 & 35.48 & 42 & 29.58 & 0.418 & 0.518 \\
& No & 20 & & 100 & & & \\
Immunologic test & Yes & 22 & 70.97 & 93 & 65.49 & 0.342 & 0.559 \\
& No & 9 & & 49 & & & \\
\hline
\end{tabular}


Table 5 Guideline adherence of treatment regimen recommendations

\begin{tabular}{|c|c|c|c|c|c|c|c|}
\hline & & Group 1 & Rate $(\%)$ & Group 2 & Rate $(\%)$ & $\chi^{2}$ & $P$ value \\
\hline No praziquantel therapy & $\begin{array}{l}\text { Yes } \\
\text { No }\end{array}$ & $\begin{array}{l}31 \\
0\end{array}$ & 100 & $\begin{array}{l}141 \\
1\end{array}$ & 99.30 & $-^{\mathrm{a}}$ & - \\
\hline Liver-protecting therapy & $\begin{array}{l}\text { Yes } \\
\text { No }\end{array}$ & $\begin{array}{l}31 \\
0\end{array}$ & 100 & $\begin{array}{l}142 \\
0\end{array}$ & 100 & - & - \\
\hline Symptomatic therapy & $\begin{array}{l}\text { Yes } \\
\text { No }\end{array}$ & $\begin{array}{l}28 \\
3\end{array}$ & 90.32 & $\begin{array}{l}132 \\
10\end{array}$ & 92.96 & 0.254 & 0.614 \\
\hline
\end{tabular}

a The subjects' distribution of no praziquantel therapy and liver-protecting therapy in two groups did not meet the criteria of chi-square test

misdiagnosis rate of schistosomiasis was shown in China because of nonstandard diagnosis procedures (Wu and Huang 2006; Zhu et al. 2010). There were various reasons as to why a misdiagnosis could occur including errors by physicians. For example, physicians in non-endemic areas were usually unfamiliar with schistosomiasis (Nguyen et al. 2012), and hence, misdiagnosis might occur (Huang and Manderson 2005). Therefore, it was very necessary for physicians to conform to guidelines to diagnose patients with advanced schistosomiasis japonica. In the study, physicians' compliance with diagnosis recommendations for clinical manifestation check and etiological examination was especially on the low side so that the two diagnosis recommendations should be conformed emphatically.

In the study, there were totally $91.91 \%$ of adequate treatment regimens. And just $13(7.51 \%)$ regimens of taking symptomatic therapy were not following guidelines, among which there are $3(3 / 31)$ in group 1 and $10(10 / 142)$ in group 2. Research reported that less than $40 \%$ of patients in the public sector and $30 \%$ in the private sector are treated according to clinical guidelines in developing countries (WHO 2010). And these clinical practices might result from irrational drug use. WHO once estimated that more than half of all medicines are prescribed, dispensed, or sold inappropriately and that half of all patients fail to take them correctly (WHO 2014; Fromer and Cooper 2008). Medically inappropriate, ineffective, and economically inefficient use of pharmaceuticals is commonly observed in the health care system throughout the world
(Editorial 2012). Researches have shown that irrational treatment could lead to praziquantel-resistant isolates of schistosomiasis (Wang et al. 2012; Cioli and Pica-Mattoccia 2003). Hence, it is crucial to improve physicians' compliance with treatment regimen recommendations of guidelines, especially in symptomatic therapy (Rumsfel 2011).

All patients with advanced schistosomiasis japonica required hospitalizations. If hospitalization days were not enough, patients would underutilize adequate treatment. And complete discharge checks would make sure whether patients leave hospital appropriately. The study found that only one $(2.23 \%)$ patient in group 1 and zero $(0 \%)$ in group 2 were in accordance with discharge criteria of guidelines, and most of the patients left hospital without symptom check (22/173), liver function and biochemical tests (4/173), and complication check (82/173). Among the 173 inpatients, the rate of adequate hospitalization days was just 36.42\%(63/173). Besides, previous studies in China have shown that the discharge checks and the hospitalization days were the main factors influencing inpatients' medical expenses and overuse (WHO 2010; Wang et al. 2009; Gurarie et al. 2010). Therefore, following discharge criteria, especially in the above three aspects of discharge check, and hospitalization of guideline recommendations could effectively lead to rational drug use, adequately treat diseases, and minimize medical service cost.

What is more, the chi-square test suggested that there was no significant difference $(P>0.05)$ on guideline adherence in

Table 6 Guideline adherence of discharge criteria recommendations

\begin{tabular}{|c|c|c|c|c|c|c|c|}
\hline & & Group 1 & Rate $(\%)$ & Group 2 & Rate $(\%)$ & $\chi^{2}$ & $P$ value \\
\hline Patient's state on discharge & $\begin{array}{l}\text { Yes } \\
\text { No }\end{array}$ & $\begin{array}{l}30 \\
1\end{array}$ & 96.77 & $\begin{array}{l}139 \\
3\end{array}$ & 97.89 & 0.14 & $0.550 F$ \\
\hline Symptom check & $\begin{array}{l}\text { Yes } \\
\text { No }\end{array}$ & $\begin{array}{l}4 \\
27\end{array}$ & 12.90 & $\begin{array}{l}18 \\
124\end{array}$ & 12.77 & 0.001 & 0.973 \\
\hline Liver function and biochemical test & $\begin{array}{l}\text { Yes } \\
\text { No }\end{array}$ & $\begin{array}{l}0 \\
31\end{array}$ & 0 & $\begin{array}{l}4 \\
138\end{array}$ & 2.82 & 0.894 & $0.344 F$ \\
\hline Complications & $\begin{array}{l}\text { Yes } \\
\text { No }\end{array}$ & $\begin{array}{l}13 \\
18\end{array}$ & 41.94 & $\begin{array}{l}69 \\
73\end{array}$ & 48.59 & 0.452 & 0.501 \\
\hline
\end{tabular}

$F$ Fisher's exact test 
the two groups in the study. The severity of advanced schistosomiasis japonica could not influence physicians' practices to adhere to guidelines. Thus, both of critical and general patients' treatments should be stressed to comply with guidelines.

To our knowledge, this is the first study to evaluate guideline adherence in the treatment for patients with advanced schistosomiasis japonica in the two groups' clinical practices. Strengths of the study include multiangle analysis of treatment procedures and the disease severity and some important application values for health sectors and policymakers. The findings of the study are subject to some limitations. Because of limited data, we did not study whether these guidelines were adequate or valid for advanced schistosomiasis treatment. Consequently, we assessed compliance based on the guideline recommendations only and did not study the subject in more depth (Richard-Tremblay et al. 2012).

\section{Conclusions}

The large gap between guidelines and the practices of treatment for patients with advanced schistosomiasis japonica was found in the study. Therefore, it is time for health sectors to take measures to standardize physicians' practice through guidelines.

\section{Ethics approval}

The study was reviewed and approved by the Research Ethics Committee of Tongji Medical College, Huazhong University of Science and Technology (IORG No: IORG0003571).

Acknowledgments Funding for the study was supported by the National Natural Science Foundation of China (Grant No.71173082). The authors would like to thank Gong'an Schistosomiasis Special Hospital and Shishou Third People's Hospital for their support of our data collection in the study as well as our teams for providing invaluable input during the earlier manuscript.

\begin{abstract}
Authors' contributions Fangying Zhong performed or supervised the analyses, interpreted the results, wrote the initial draft, provided substantive suggestions for revision on the manuscript, and contributed statistical expertise. Chenxi Liu assembled the data and provided substantive suggestions for revision. Xinping Zhang conceived, designed or planned the study, interpreted the results, provided substantive suggestions for revision on subsequent iterations of the manuscript, and provided study materials and administrative, technical, and logistical support.
\end{abstract}

Conflict of interest All the authors declare that there are no potential conflicts of interest, including any financial, personal, or other relationship with other people or organizations that could inappropriately influence this work.

Open Access This article is distributed under the terms of the Creative Commons Attribution License which permits any use, distribution, and reproduction in any medium, provided the original author(s) and the source are credited.

\section{References}

Bampton PA, Sandford JJ, Young GP (2007) Achieving long-term compliance with colonoscopic surveillance guidelines for patients at increased risk of colorectal cancer in Australia. Int J Clin Pract 61:510-513

Chen XB (2002) Modern parasitology. People Military Medical Press, Beijing

Chen Y (2007) The study on factors influencing on clinicians' diagnosis and treatment behavior. Shandong University, Ji'nan

Cioli D, Pica-Mattoccia L (2003) Praziquantel. Parasitol Res 90:S3-S9

Cretin S, Farley DO, Dolter KJ, Nicholas W (2007) Evaluating an integrated approach to clinical quality improvement: clinical guidelines, quality measurement, and supportive system design. Med Care 39:70-84

Diagnosis R (2014) How common is misdiagnosis. RightDiagnosis.com, U.S.A

Editorial (2012) Rational drug use-as common as common sense. Med J Armed Forces India 68:206-208

Feng T, Xu J, Hang DR (2011) Conditions of schistosomiasis laboratories at county level. Chin J Schisto Control 23:370-376

Fenwick A, Webster JP, Bosque-Oliva E, Blair L, Fleming FM, Zhang Y, Garba A, Stothard JR, Gabrielli AF, Clements ACA, Kabatereine NB, Toure S, Dembele R, Nyandindi U, Mwansa J, Koukounari A (2009) The Schistosomiasis Control Initiative (SCI): rationale, development and implementation from 2002-2008. Parasitology 136:1719-1730

Fritz JM, Cleland JA, Brennan GP (2007) Does adherence to the guideline recommendation for active treatments improve the quality of care for patients with acute low back pain delivered by physical therapists. Med Care 45:973-980

Fromer L, Cooper CB (2008) A review of the GOLD guidelines for the diagnosis and treatment of patients with COPD. Int J Clin Pract 62: 1219-1236

Gurarie D, King CH, Wang X (2010) A new approach to modelling schistosomiasis transmission based on stratified worm burden. Parasitology 137:1951-1965

Hope K, Jason L, Valerie F (2008) Improving physician adherence to clinical practice guidelines. New England Healthcare Institute, New England

Huang YX, Manderson L (2005) The social and economic context and determinants of schistosomiasis japonica. Acta Trop 96:223-231

Larson E (2003) Status of practice guidelines in the United States: CDC guidelines as an example. Prev Med 36:519-524

Lugtenberg M (2011) Guideline adherence in practice: exploring the gap between theory and practice. Tilburg University, Tilburg

Ma SQ, Zhong XH (2004) Probe into the problem of irrational behavior of disease diagnosis and treatment. Chin Hosp Manag 24:39-40

Marciano NJ, Merlin TL, Bessen T, Street JM (2014) To what extent are current guidelines for cutaneous melanoma follow up based on scientific evidence. Int J Clin Pract 68:761-770

McCormack JP, Loewen P (2007) Adding "value" to clinical practice guidelines. Can Fam Physician 53:1326-1327

McGlynn EA, Asch SM, Adams J, Keesey J, Hicks J, DeCristofaro A, Kerr EA (2003) The quality of health care delivered to adults in the United States. N Engl J Med 348:2635-2645

Moonen B, Cohe JM (2011) Text messaging to improve adherence to malaria guidelines. Lancet 378:750-752

Nguyen HM, Schiavoni A, Scot KD, Tanios MA (2012) Implementation of sepsis management guideline in a community-based teaching hospital - can education be potentially beneficial for septic patients. Int J Clin Pract 66:705-710

Reed K, May R (2011) Patient safety in American hospitals study. Health Grades, Denver

Ren GH (2009) Clinical study of schistosomiasis. People's Medical Publishing House, Beijing

Richard-Tremblay AA, Sheehy O, Audibert F, Ferreira E, Bérard A (2012) Concordance between periconceptional folic acid 
supplementation and Canadian clinical guidelines. J Popul Ther Clin Pharmacol 19:150-159

Rumsfel D (2011) Guiding the guideline. Lancet 377:1125

Schwentner L, Wöckel A, König J, Janni W, Ebner F, Blettner M, Kreienberg R, Ewijk RV (2013) Adherence to treatment guidelines and survival in triple-negative breast cancer: a retrospective multicenter cohort study with 9156 patients. BMC Cancer 13:487-497

Shao H (2012) Strengthen the compliance of subject guidelines. Med Philos 33:465

Walter ND, Lyimo T, Skarbinski J, Metta E, Kahigwa E, Flannery BD, Abdulla S, Kachur SP (2009) Why first-level health workers fail to follow guidelines for managing severe disease in children in the coast region, the United Republic of Tanzania. Bull WHO 87:99-107

Wang YF, Xu LZ, Zhou CC (2009) Path analysis on determinants of tuberculosis inpatient cost in Shandong province. Chin J Health Stat $26: 27-28$
Wang W, Wang L, Liang YS (2012) Susceptibility or resistance of praziquantel in human schistosomiasis: a review. Parasitol Res 111:1871-1877

WHO (2006) Preventive chemotherapy in human helminthiasis. World Health Organisation, Geneva

WHO (2010) Rational use of medicines. World Health Organisation, Geneva

WHO (2014) The pursuit of responsible use of medicines: sharing and learning from country experiences. World Health Organisation, Geneva

Wu W, Huang YX (2006) Misdiagnosis of acute schistosomiasis and diagnostic treatment with praziquantel. J Pathog Biol 1:307-308

Zhu HP, Yu CH, Xia X, Dong GY, Tang J, Fang L, Du YK (2010) Assessing the diagnostic accuracy of immunodiagnostic techniques in the diagnosis of schistosomiasis japonica: a meta-analysis. Parasitol Res 107:1067-1073 